Once you have Acrobat Reader open on your computer, click on the Comment tab at the right of the toolbar:

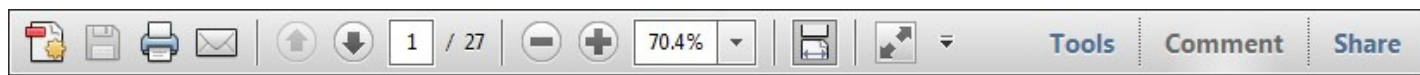

This will open up a panel down the right side of the document. The majority of tools you will use for annotating your proof will be in the Annotations section, pictured opposite. We've picked out some of these tools below:

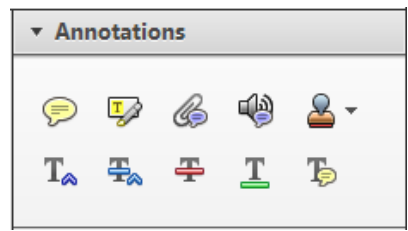

1. Replace (Ins) Tool - for replacing text.

Tistikes a line through text and opens up a text box where replacement text can be entered.

How to use it

- Highlight a word or sentence.

- Click on the Replace (Ins) icon in the Annotations section.

- Type the replacement text into the blue box that appears.

ıdard tramework for the analysis of $\mathrm{m}$ icy-Nevertheless, it also led to exog،

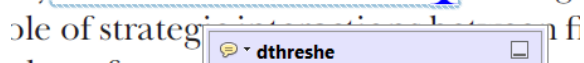
aber of comp 08/06/2011 15:58:17 $\quad$ O is that the $\mathrm{s} 1$, which led of nain compo: be level, are exc nc

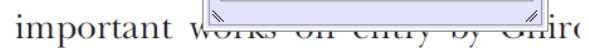
M heneforth) 1 we onen the 'hlarle $\mathrm{t}$

3. Add note to text Tool - for highlighting a section to be changed to bold or italic.

T) Highlights text in yellow and opens up a text box where comments can be entered.

How to use it

- Highlight the relevant section of text.

- Click on the Add note to text icon in the Annotations section.

- Type instruction on what should be changed regarding the text into the yellow box that appears.

namic responses of mark ups ent with the VAR evidence

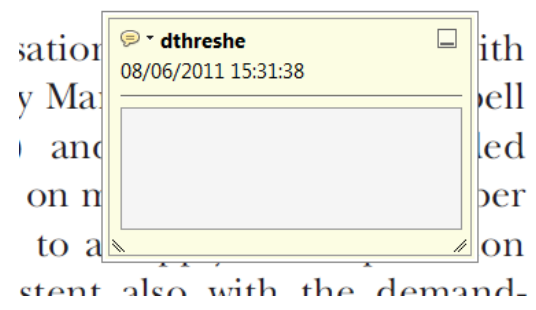

2. Strikethrough (Del) Tool - for deleting text.

T Strikes a red line through text that is to be deleted.

How to use it

- Highlight a word or sentence.

- Click on the Strikethrough (Del) icon in the Annotations section.

there is no room for extra protits al s ups are zero and the number of zet) values are not determined by Blanchard and Kiyotaki (1987), sfect competition in general equilil ts of aggregate demand and supply lassical framework assuming monol een on evorenous number of firme

4. Add sticky note Tool - for making notes at specific points in the text.

Marks a point in the proof where a comment needs to be highlighted.

How to use it

- Click on the Add sticky note icon in the Annotations section.

- Click at the point in the proof where the comment should be inserted.

- Type the comment into the yellow box that appears.

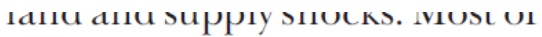

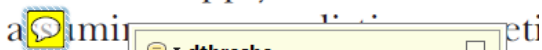

numbe $\mid \begin{aligned} & \ominus \text {-dthreshe } \\ & 08 / 06 / 2011 \text { 15:18:08 }\end{aligned}$

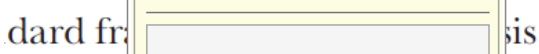

cy. Nev pa

le of st $\square$ wi

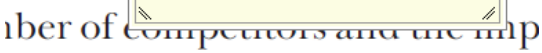

is that the structure of the secto 
5. Attach File Tool - for inserting large amounts of text or replacement figures.

Inserts an icon linking to the attached file in the appropriate place in the text.

\section{How to use it}

- Click on the Attach File icon in the Annotations section.

- Click on the proof to where you'd like the attached file to be linked.

- Select the file to be attached from your computer or network.

- Select the colour and type of icon that will appear in the proof. Click OK.

\section{E N D}

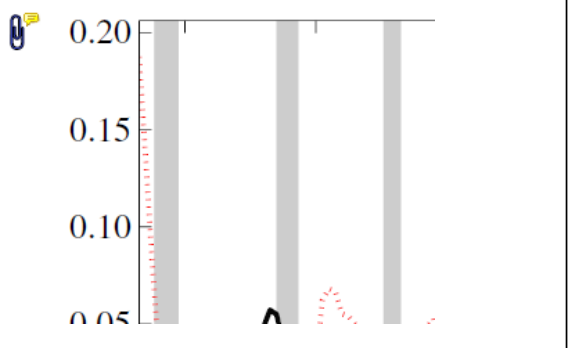

6. Drawing Markups Tools - for drawing shapes, lines and freeform annotations on proofs and commenting on these marks. Allows shapes, lines and freeform annotations to be drawn on proofs and for comment to be made on these marks.

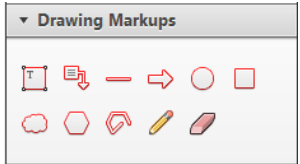

How to use it

- Click on one of the shapes in the Drawing Markups section.

- Click on the proof at the relevant point and draw the selected shape with the cursor.

- To add a comment to the drawn shape, move the cursor over the shape until an arrowhead appears.

- Double click on the shape and type any text in the red box that appears.

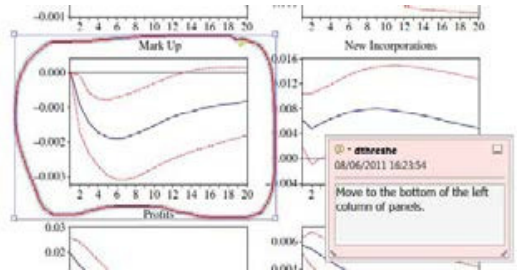




\title{
X-ray Absorption Spectroscopy Studies of the Room-Temperature Ferromagnetic Fe-Doped $6 \mathrm{H}-\mathrm{BaTiO}_{3}$
}

\author{
Iuliia Mikulska, ${ }^{\ddagger}$ Matjaž Valant, ${ }^{\ddagger \dagger}$ Iztok Arčon, ${ }^{\ddagger, \S}$ and Darja Lisjak ${ }^{\natural}$ \\ ${ }^{\star}$ University of Nova Gorica, Nova Gorica SI-5000, Slovenia

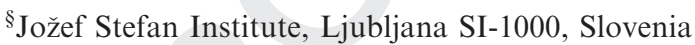

2 "Advanced Materials Department, Jožef Stefan Institute, Ljubljana SI-1000, Slovenia

\begin{abstract}
We investigated the effect of annealing temperature on magnetic properties of $2 \%$ and $10 \%$ Fe-doped $\mathrm{BaTiO}_{3}$. To understand the possible structural differences between samples treated at different annealing temperatures, and to correlate them with the magnetic properties, several characterization techniques, such as X-ray diffraction and X-ray absorption spectroscopic methods (XANES and EXAFS) were employed. We found that the $2 \%$ Fe-doped $\mathrm{BaTiO}_{3}$ pseudocubic perovskite is paramagnetic regardless of the heat-treatment conditions. Initially paramagnetic $10 \%$ Fe-doped $6 \mathrm{H}-\mathrm{BaTiO}_{3}$, treated at $1250^{\circ} \mathrm{C}$, became ferromagnetic after additional annealing at higher temperature. We have crystalographically characterized the cation ordering processes in the $6 \mathrm{H}-\mathrm{BaTiO}_{3}$ that occurred during the high-temperature annealing. The ferromagnetism that is induced in this stage is most probably associated with the observed diffusion processes but it extrinsic character still cannot be fully disregarded.
\end{abstract}

\section{Introduction}

Imultaneous presence of semiconducting and ferromagnetic properties makes dilute magnetic oxide (DMO) materials attractive for application in spintronic and magnetoelectronic devices. ${ }^{1-3}$ The room-temperature magnetism in the wide bandgap semiconductors would be of the immense technological importance only if the magnetic coupling is of intrinsic character and not a consequence of paramagnetic dopant segregation or any other extrinsic reason.

Some of the investigated DMO candidates possess roomtemperature ferromagnetism when doped with a small percentage of transition metal ions, for example, Mn-doped $\mathrm{ZnO},{ }^{4} \mathrm{Fe}$-doped $\mathrm{SnO}_{2}{ }^{5}$ Even for these well investigated systems still some disputes over the intrinsic nature of the magnetism exists. ${ }^{6,7}$ Another very promising DMO material is Fe-doped $\mathrm{BaTiO}_{3}$. Due to the observed room-temperature magnetism it is very intensively investigated material in a wide range of dopant concentration. ${ }^{8-20}$

However, the reports on the properties of this material are extremely controversial. The first source of this controversy is in the phase transition that occurs with $\mathrm{Fe}$ doping and is often not properly considered. It is known that tetragonal perovskite $\mathrm{BaTiO}_{3}$ can accommodate about $1 \%$ of $\mathrm{Fe}^{3+}$ on the perovskite $\mathrm{B}$ site. ${ }^{13,21}$ Depending on the synthesis condi-

A. Belik—contributing editor

\footnotetext{
Manuscript No. 35454. Received August 12, 2014; revised November 21, 2014; approved November 24, 2014

${ }^{\dagger}$ Author to whom correspondence should be addressed. e-mail: matjaz.valant@ung.
}

tions from $6 \%$ to $13 \%$ of $\mathrm{Fe}$ is required to fully stabilize the hexagonal $6 \mathrm{H}-\mathrm{BaTiO}_{3}$ structure. ${ }^{17,21-23}$ The intermediate dopant concentrations yield two phase mixture. ${ }^{13,21}$ However, the literature reports claim the intrinsic room-temperature magnetism for the dopant levels from $2 \%$ to $10 \%$, although no $\mathrm{BaTiO}_{3}$ phase in its bulk form can contain such $\mathrm{Fe}$ concentration. Of course, with the increase in the nominal Fe concentration toward $10 \%$, the saturation magnetization of the biphasic mixture increases as the amount of the paramagnetic phase reduces. It would also be expected that an increase in the $\mathrm{Fe}$ content in $\mathrm{Fe}$-doped $6 \mathrm{H}-\mathrm{BaTiO}_{3}$ phase would enhance the magnetic ordering. Interestingly, it has been shown the opposite: the saturation magnetization of the low end-member with $10 \%$ of $\mathrm{Fe}$ is the highest while any increase in $\mathrm{Fe}$ content causes a gradual decrease in the magnetism until the material becomes paramagnetic at doping level of $70 \%{ }^{11,13}$

Despite intensive research and a number of reports that claim the room-temperature ferromagnetism in Fe-doped $\mathrm{BaTiO}_{3}$ the origin of the magnetic coupling still remains unknown. ${ }^{10-13,17,21,24}$ Some authors claim that the room-temperature ferromagnetism is attributed to some structural characteristics, such as ordering of oxygen vacancies ${ }^{8}$ or $\mathrm{Fe}$ pairing on $\mathrm{Ti}(2)$ sites $^{12,25}$ whereas others attribute the ferromagnetic behavior to the double exchange interaction, due to the simultaneous presence of $\mathrm{Fe}^{3+}$ and $\mathrm{Fe}^{2+}$ or $\mathrm{Fe}^{4+}$ valance states. ${ }^{15,16,23}$ Also, there are assumptions that $\mathrm{Ti}^{4+}$ partially reduces to $\mathrm{Ti}^{3+}$, which can contribute to the ferromagnetic coupling. ${ }^{8}$ In our previous study ${ }^{26}$ on $20 \% \mathrm{Fe}$ doped $6 \mathrm{H}-\mathrm{BaTiO}_{3}$ we showed that $\mathrm{Fe}^{3+}$ ions undergo an ordering process with a prolonged high-temperature annealing, which plays a crucial role in induction of the magnetic coupling. We showed that the same batch can be paramagnetic or exhibit some ferromagnetic coupling depending on the degree of the cation ordering. We have described the atomistic mechanism of the ordering and identified the driving force of the ordering to be in reduction in electrostatic repulsion on the $\mathrm{Ti}(2)$ sites.

In the light of the newly discovered diffusion processes in Fe-doped $6 \mathrm{H}-\mathrm{BaTiO}_{3}$, which are of crucial importance for its functional properties, ${ }^{25,26}$ we also decided to thoroughly investigate the low-concentration range of this system, that is, the range of $\leq 10 \%$. First, we made a clear distinction between properties of the Fe-doped paramagnetic tetragonal $\mathrm{BaTiO}_{3}$ and $6 \mathrm{H}-\mathrm{BaTiO}_{3}$ phases. We performed a microscopic structural analysis on the $6 \mathrm{H}$ low end-member, $10 \%$ Fe-doped $6 \mathrm{H}-\mathrm{BaTiO}_{3}$, with intention to understand the possible structural differences between samples treated at different annealing temperatures. We correlated this to magnetic properties and to the similar diffusion processes in highly doped Fe-doped $6 \mathrm{H}-\mathrm{BaTiO}_{3}$ to fully describe the crystal chemistry of the entire concentration range that is interesting for the DMO applications. 
Here, we have described the ordering processes which are crucial for the establishing of the long-range ferromagnetic coupling in Fe-doped $6 \mathrm{H}-\mathrm{BaTiO}_{3}$. Our convincing experimental results bring us closer to understanding the origin of magnetic coupling in this system.

\section{Experimental Procedure}

Fe-doped $\mathrm{BaTiO}_{3}$ samples with nominal composition of $\mathrm{BaTi}_{1-x} \mathrm{Fe}_{x} \mathrm{O}_{3-\delta}(x=0.02,0.1)$ were synthesized by conventional solid-state reaction method by stoichiometric mixing of raw oxide materials of $\mathrm{Fe}_{2} \mathrm{O}_{3}, \mathrm{TiO}_{2}$, and $\mathrm{BaCO}_{3}$. Before each heat treatment, the samples were mixed by grinding in planetary mill at $200 \mathrm{rpm}$ for $1 \mathrm{~h}$ in ethanol ambient, dried at $70^{\circ} \mathrm{C}$ and pressed into $3-4 \mathrm{~g}$ pellets. First, the pellets were calcined at $1000^{\circ} \mathrm{C}$ for $5 \mathrm{~h}$. Then, $2 \% \mathrm{Fe}$-doped $\mathrm{BaTiO}_{3}$ was treated at $1200^{\circ} \mathrm{C}$ for $5 \mathrm{~h}$, whereas $10 \%$ Fe-doped $\mathrm{BaTiO}_{3}$ was fired twice at $1250^{\circ} \mathrm{C}$ for $5 \mathrm{~h}$. After this synthesis step, the obtained powders were divided into two parts. One of these parts was additionally annealed at $1400^{\circ} \mathrm{C}$ for $5 \mathrm{~h}$ for $2 \% \mathrm{Fe}$-doped $\mathrm{BaTiO}_{3}$, and at $1500^{\circ} \mathrm{C}$ for $10 \mathrm{~h}$ for $10 \%$ Fe-doped $\mathrm{BaTiO}_{3}$. All heat treatments were carried out in oxygen atmosphere.

The crystal structure of the samples was analyzed by 3 X-Ray diffractometry (PANalytical X'PRO). The XRD patterns were performed in reflection (Bragg-Brentano) mode using $\mathrm{Cu} K_{\alpha}$ radiation. Data were collected in the range $15^{\circ}-2 \theta \leq 90^{\circ}$ with the scan step of $0.008^{\circ}$ and with scan step time of $25 \mathrm{~s}$.

The Fe K-edge X-ray absorption spectroscopy (XAS) spectra were collected at the beamline C of HASYLAB at DESY in Hamburg (Germany) simultaneously in fluorescence and transmission detection modes. Ti K-edge XANES spectra were measured at the XAFS beamline of the ELETTRA synchrotron radiation facility in Trieste (Italy) in transmission detection mode. All experimental details are described in our previous study. ${ }^{26}$ The Fe and Ti XAS spectra were analyzed with the IFEFFIT program package. ${ }^{27}$ Magnetization was measured as function of applied magnetic field on vibrating sample magnetometer (VSM, LakeShore, 7404) at room temperature.

\section{Results and Discussion}

The crystal structure of the samples was analyzed by XRD. $2 \%$ Fe-doped $\mathrm{BaTiO}_{3}$ sample treated at $1200^{\circ} \mathrm{C}$ has tetragonal crystal structure (space group $P 4 m m$ ) with possible traces of hexagonal phase (space group P63/mmc) (Fig. 1). The XRD pattern of $2 \%$ Fe-doped $\mathrm{BaTiO}_{3}$ additionally annealed at $1400^{\circ} \mathrm{C}$ for $5 \mathrm{~h}$ indicates the presence of mixture of hexagonal and tetragonal phases. In addition to prevailing $6 \mathrm{H}$ phase the sample with $10 \%$ of $\mathrm{Fe}$ treated at $1250^{\circ} \mathrm{C}$ contains minor amount of the tetragonal perovskite phase. The sample additionally annealed at $1500^{\circ} \mathrm{C}$ shows a single-phase composition with only $6 \mathrm{H}-\mathrm{BaTiO}_{3}$ phase. Our results confirm the main claims of other authors ${ }^{8,13,21}$ that the solid solubility limit of $\mathrm{Fe}$ in the tetragonal $\mathrm{BaTiO}_{3}$ is below 2 at. $\%$, whereas about 10 at. $\%$ of $\mathrm{Fe}$ is required to fully stabilize $6 \mathrm{H}-\mathrm{BaTiO}_{3}$. In addition, it can be concluded that the low-end stability range of $\mathrm{Fe}$-doped $6 \mathrm{H}-\mathrm{BaTiO}_{3}$ is temperature dependent: more than $10 \%$ of $\mathrm{Fe}$ are needed for stabilization of the structure at $1250^{\circ} \mathrm{C}$ and below $10 \%$ at higher temperature of $1500^{\circ} \mathrm{C}$.

First, we have measured the magnetic properties of the tetragonal perovskite phase with the highest possible Fe concentration (i.e., $2 \%$ ). Regardless the thermal treatment conditions, the paramagnetic behavior has been determined. Magnetization at room temperature as a function of applied magnetic field is shown on Fig. 2.

As the tetragonal perovskite phase is paramagnetic the magnetic properties of the two-phase region between $2 \%$ and

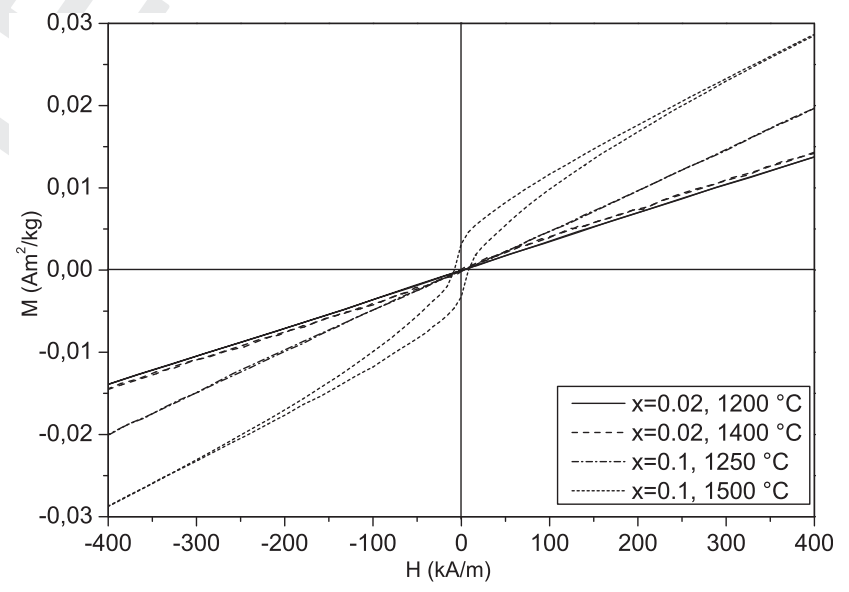

Fig. 2. Room-temperature $\mathrm{M}(\mathrm{H})$ loops for $2 \%$ and $10 \%$ Fe-doped $\mathrm{BaTiO}_{3}$ samples treated at different annealing temperatures.
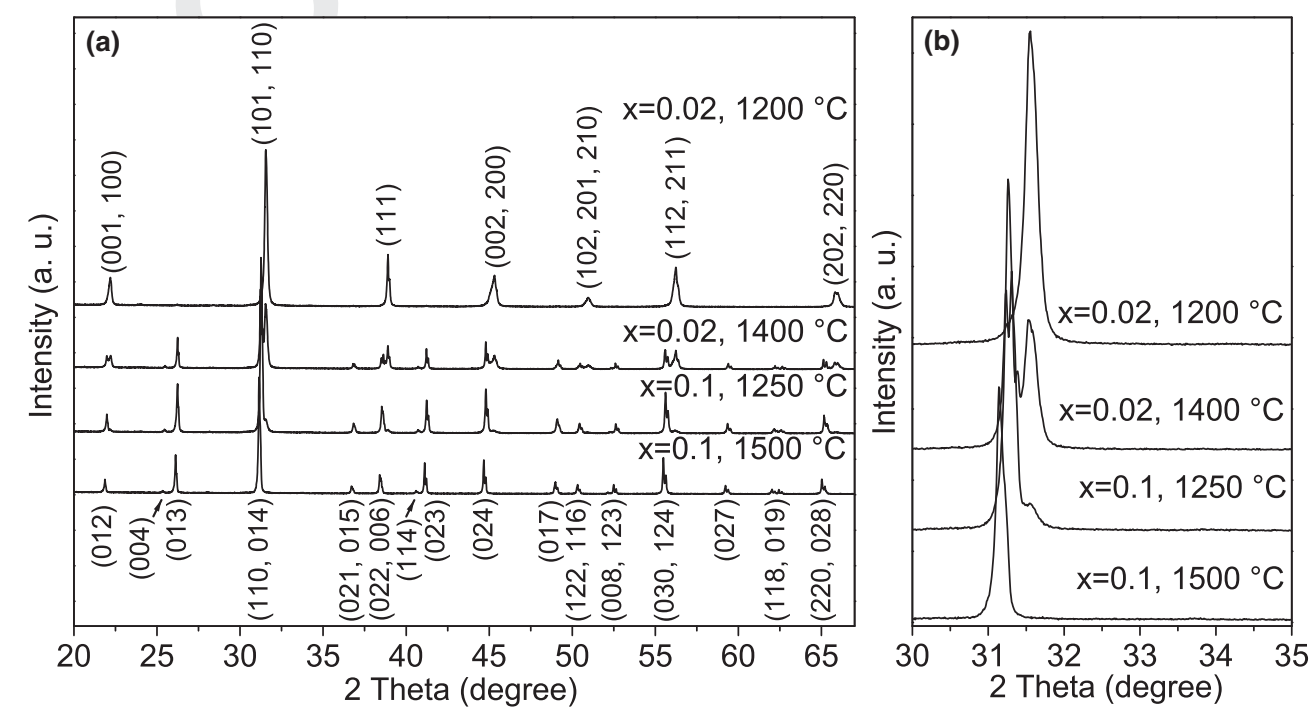

Fig. 1. (a) X-ray diffraction patterns of $\mathrm{BaTi}_{1-x} \mathrm{Fe}_{x} \mathrm{O}_{3}$ powder samples treated at different annealing temperatures. The peaks of tetragonal (top) and hexagonal (bottom) $\mathrm{BaTiO}_{3}$ are labeled with Miller indices $(h k l)$. (b) Magnification of diffraction peaks in the $2 \theta$ interval $30^{\circ}-34^{\circ}$, which shows the effect of annealing temperature on the phase evolution of Fe-doped $\mathrm{BaTiO}_{3}$. 
$10 \%$ of $\mathrm{Fe}$ are dominated by the ferromagnetic properties of the $6 \mathrm{H}$ phase; therefore, this region has not been of our main interest. We analyzed the sample with $10 \%$ of $\mathrm{Fe}$ that was treated at $1250^{\circ} \mathrm{C}$, which has predominant $6 \mathrm{H}-\mathrm{BaTiO}_{3}$ phase with a miniscule amount of the paramagnetic tetragonal phase. The sample exhibits pure paramagnetic behavior, so we can conclude that the dominating $6 \mathrm{H}$ matrix phase is also paramagnetic. The same sample was additionally annealed at $1500^{\circ} \mathrm{C}$ and the magnetic measurements showed that this stage of the thermal treatment has induced the ferromagnetic behavior (Fig. 2). Despite the hysteretic behavior the magnetization increases linearly with the increasing magnetic field above $50 \mathrm{kA} / \mathrm{m}$, indicating that ferromagnetic and paramagnetic phases coexist in the sample.

To correlate the observed variation in the magnetic properties with microscopic processes at atomic level, that occur in the $10 \% \mathrm{Fe}$-doped $6 \mathrm{H}-\mathrm{BaTiO}_{3}$ during thermal treatment, we performed a detailed analysis of $\mathrm{Fe}$ valence state and local structure around Fe cations in the crystal structure by Fe K-edge XANES and EXAFS.

To verify the possible changes in the valance state of the $\mathrm{Fe}$ cations in the $10 \%$ Fe-doped $6 \mathrm{H}-\mathrm{BaTiO}_{3}$ samples we analyzed Fe K-edge XANES spectra (Fig. 3). A decrease in

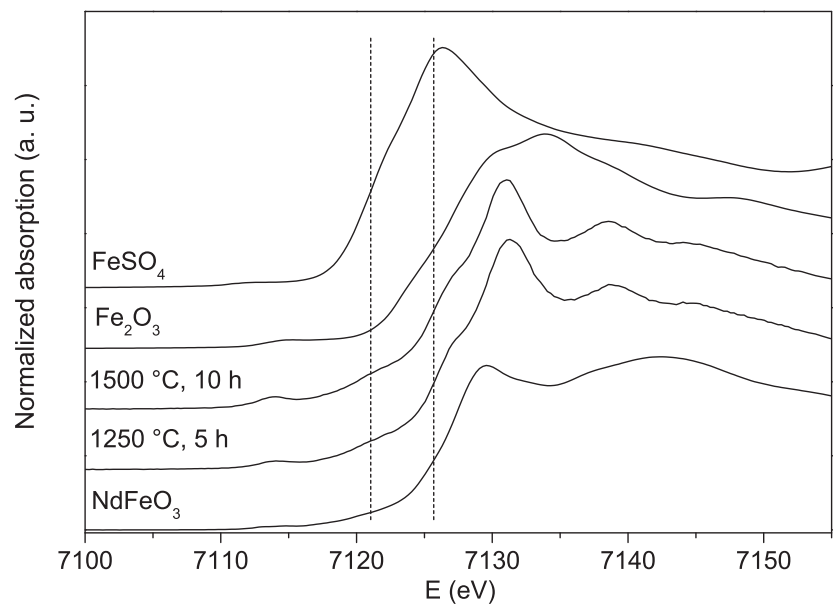

Fig. 3. Normalized Fe K-edge XANES spectra measured on the $10 \%$ Fe-doped $6 \mathrm{H}-\mathrm{BaTiO}_{3}$ samples after the different heat treatments and reference compounds $\left[\mathrm{Fe}(\mathrm{III})_{2} \mathrm{O}_{3}, \mathrm{NdFe}(\mathrm{III}) \mathrm{O}_{3}\right.$, and $\left.\mathrm{Fe}(\mathrm{II}) \mathrm{SO}_{4}\right]$ with known $\mathrm{Fe}$ valance state. Two vertical lines are plotted at the position of the $\mathrm{Fe}(\mathrm{II}) \mathrm{K}$-edge $(7121 \mathrm{eV}$ ) and $\mathrm{Fe}(\mathrm{III}) \mathrm{K}$ edge $(7125.7 \mathrm{eV})$ for comparison of the Fe K-edge positions.

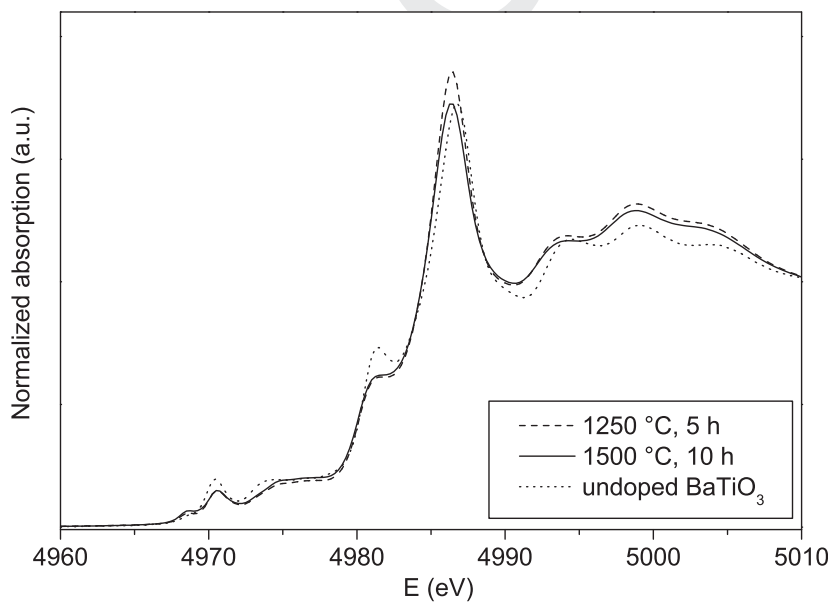

Fig. 4. Normalized Ti K-edge XANES spectra measured on $10 \%$ Fe-doped $6 \mathrm{H}-\mathrm{BaTiO}_{3}$ powder samples, treated at different annealing temperatures $\left(1250^{\circ} \mathrm{C}\right.$ and $\left.1500^{\circ} \mathrm{C}\right)$, and undoped $\mathrm{BaTiO}_{3}$ with tetragonal (space group $\mathrm{P} 4 \mathrm{~mm}$ ) crystal structure as a standard for $\mathrm{Ti}^{4+}$. the oxidation state of the absorbing atom shifts the energy position of the absorption edge to the lower energies. A shift of about $4.5 \mathrm{eV}$ is observed between $\mathrm{Fe}^{3+}$ and $\mathrm{Fe}^{2+}$ in reference compounds with well-established $\mathrm{Fe}$ valance states $\left(\mathrm{Fe}^{3+}\right.$ in $\mathrm{Fe}_{2} \mathrm{O}_{3}$ and $\mathrm{NdFeO}_{3}$, and $\mathrm{Fe}^{2+}$ in $\left.\mathrm{FeSO}_{4}\right)$, in agreement with previous observations. ${ }^{28,29}$ XANES spectra of

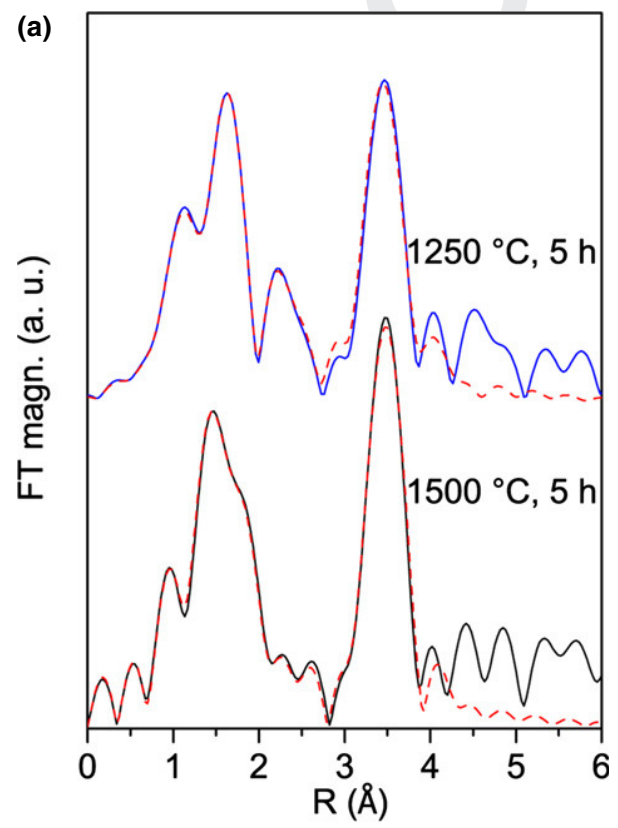

(b)

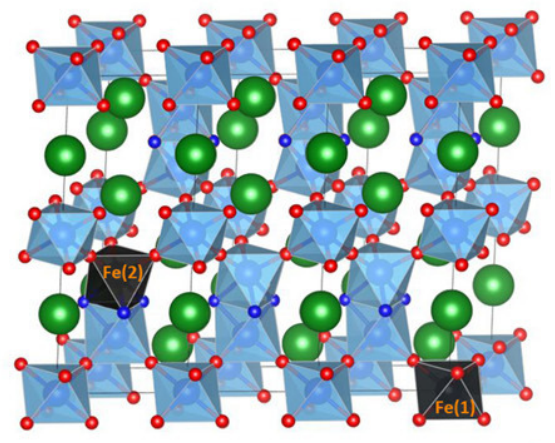

(c)

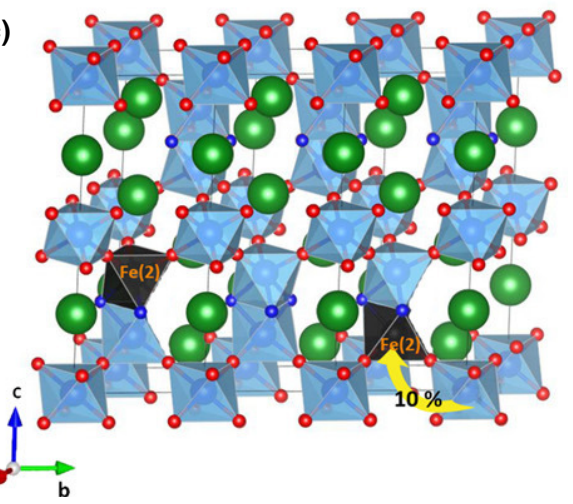

Fig. 5. (a) The Fourier-transform magnitudes of $10 \%$ Fe-doped $\mathrm{BaTiO}_{3}$ annealed at different temperatures (dashed line - best fit EXAFS model). (b) and (c) Schematic view of the Fe-distribution within three unit cells of the $\mathrm{Fe}$-doped $6 \mathrm{H}-\mathrm{BaTiO}_{3}$ crystal structure (space group P63/mmc): (b) after treatment at $1250^{\circ} \mathrm{C}$ for $5 \mathrm{~h}$, (c) additionally annealed at $1500^{\circ} \mathrm{C}$ for $10 \mathrm{~h}$. The polyhedra represent octahedrally coordinated $\mathrm{Ti}$ atoms. The Fe atoms incorporated onto $\operatorname{Ti}(1)$ and $\operatorname{Ti}(2)$ sites and their coordination octahedra are marked black. The octahedra with missing faces illustrate the oxygen vacancy in the corresponding face-sharing plane. The big spheres are $\mathrm{Ba}$ atoms. The dark and light smaller spheres are oxygen atoms on the $\mathrm{O}(2)$ and $\mathrm{O}(1)$ crystallographic sites, respectively. The arrow marks the movements of $\mathrm{Fe}^{3+}$ from $\mathrm{Ti}(1)$ sites to $\mathrm{Ti}(2)$ sites after additional annealing at $1500^{\circ} \mathrm{C}$ for $10 \mathrm{~h}$. 
both samples exhibit similar shape and the same energy position of Fe K-edge and preedge resonances. Small differences in the edge profile and intensity of the preedge resonances can be attributed to changes in average local environment of $\mathrm{Fe}$ cations, detected in the $\mathrm{Fe} \mathrm{K}$-edge EXAFS analysis. ${ }^{28}$ Comparison of the $\mathrm{Fe} \mathrm{K}$-edge energy positions of the samples and reference compounds reveals that all iron atoms in the samples are in trivalent form.

Comparison of Ti K-edge XANES spectra of the different Fe-doped $6 \mathrm{H}-\mathrm{BaTiO}_{3}$ samples shows that spectra are identical (Fig. 4). The Ti K-edge spectrum of the reference undoped tetragonal perovskite $\mathrm{BaTiO}_{3}$, which is a wellestablished reference for $\mathrm{Ti}^{4+}$ valence state, slightly differs in the shape of the edge and preedge features compared with spectra of the two samples, due to the difference in the crystal structures. However, the energy position of the Ti K-edge in the samples coincides well with that in undoped perovskite $\mathrm{BaTiO}_{3}$, so we can conclude that all titanium in the $6 \mathrm{H}-\mathrm{Ba}-$ $\mathrm{TiO}_{3}$ samples is in tetravalent state.

We used EXAFS analysis to determine the possible changes in local environment of $\mathrm{Fe}$ atoms incorporated onto $\mathrm{Ti}(1)$ and $\mathrm{Ti}(2)$ crystallographic sites. Ti cations in $6 \mathrm{H}-\mathrm{Ba}-$ $\mathrm{TiO}_{3}$ have two different crystallographic sites: Ti(1) and Ti(2) atoms are situated in the corner-sharing and face-sharing octahedra, respectively. On both crystallographic sites $\mathrm{Ti}$ cations in $6 \mathrm{H}-\mathrm{BaTiO}_{3}$ are octahedrally coordinated, however, they have small, but significant differences in the local surroundings. ${ }^{26}$

The EXAFS signal is a superposition of two signals, one from the $\mathrm{Fe}(1)$ atoms located at $\mathrm{Ti}(1)$ site and the other, arising from $\mathrm{Fe}(2)$ atoms located at $\mathrm{Ti}(2)$ site. Contributions of individual shells of atoms around $\mathrm{Fe}$ atom are visible up to about $5 \mathrm{~A}$ in Fourier-Transform (FT) magnitudes of representative EXAFS spectra. Fourier Transform (FT) of $\mathrm{Fe}$ $\mathrm{K}$-edge EXAFS signals consist of contributions from two $\mathrm{Fe}$ coordination shells: first shell is the contribution of the oxygen atoms and one titanium atom, second shell is superimposed contribution of the barium and titanium atoms (Fig. 5). Qualitative EXAFS analysis shows that the local neighborhood of $\mathrm{Fe}$ in all samples of Fe-doped $\mathrm{BaTiO}_{3}$ is similar, with small but significant differences in the first and second coordination shells.

The quantitative information on $\mathrm{Fe}$ local structure around the $\mathrm{Ti}(1)$ and $\mathrm{Ti}(2)$, that is, $\mathrm{Fe}(1)$ and $\mathrm{Fe}(2)$, crystallographic sites was obtained from quantitative EXAFS analysis EXAFS spectra were modeled with an ab initio FEFF ${ }^{30}$ calculation using simultaneous fit of the Fe EXAFS spectra of $10 \% \mathrm{Fe}$-doped $\mathrm{BaTiO}_{3}$ sample sintered at $1250^{\circ} \mathrm{C}$ for $5 \mathrm{~h}$ and $10 \% \mathrm{Fe}$-doped $\mathrm{BaTiO}_{3}$ sample additionally annealed at $1500^{\circ} \mathrm{C}$ for $10 \mathrm{~h}$. EXAFS spectra have been fitted using similar model, as in our previous EXAFS study of $20 \%$ Fe-doped $\mathrm{BaTiO}_{3}{ }^{26}$ Two FEFF models with iron atoms incorporated onto $\mathrm{Ti}(1)$ and $\mathrm{Ti}(2)$ crystallographic sites were constructed, based on the $6 \mathrm{H}-\mathrm{BaTiO}_{3}$ crystal structure with $P 63 / m m c$ space group $(a=5.7240 \AA$ and $c=13.9650 \AA) .{ }^{31}$ Measured EXAFS spectra were modeled with a linear combination of both FEFF models, where relative amount of each model signal $\left(\mathrm{X}_{\mathrm{Fe}(1)}\right.$ and $\left.\mathrm{X}_{\mathrm{Fe}(2)}\right)$-representing the occupancy of $\mathrm{Fe}$ on each $\mathrm{Ti}$ site was allowed to vary in the EXAFS fit. Models include two neighbor shells, comprising all singlescattering and significant multiple-scattering paths with length of up to $4.52 \AA$. The structure parameters (type and neighbor atoms, distances and Debye-Waller factors) of nearest neighbor shells around $\mathrm{Fe}$ incorporated onto $\mathrm{Ti}(1)$ and $\mathrm{Ti}(2)$ sites in $10 \% \mathrm{Fe}$-doped $\mathrm{BaTiO}_{3}$ are listed in the Table I. The fit of the both EXAFS spectra was performed with the background corefinement. ${ }^{27}$

In FEFF models we allow to vary separately the common shift of the energy origin $\left(\Delta E_{0}\right)$, occupation probability of $\mathrm{Fe}$ in $\mathrm{Ti}(2)$ crystallographic site $\left(\mathrm{X}_{\mathrm{Fe}(2)}\right)$ the distances and Debye-Waller factors for the first four single-scattering $[\mathrm{Fe}(1)-\mathrm{O}$ $(1 / 1), \mathrm{Fe}(2)-\mathrm{O}(2 / 1), \mathrm{Fe}(2)-\mathrm{O}(2 / 2)$, and $\mathrm{Fe}(2)-\mathrm{Ti}(2 / 1)]$ paths. For the rest of the paths the general linear expansion coefficient was allowed to vary to compute distances, whereas correlated Debye model was used to determine the DebyeWaller factors by varying the Debye temperature parameter. In addition, $\mathrm{Fe}(2)-\mathrm{Ba}(2 / 1), \mathrm{Fe}(2)-\mathrm{Ba}(2 / 3)$, and $\mathrm{Fe}(1)-\mathrm{Ba}(1 / 2)$ distances were allowed to vary separately. The site occupation probabilities of $\mathrm{Fe}$ in $\mathrm{Ti}(1)$ and $\mathrm{Ti}(2)$ sites were constrained to a unit sum. The amplitude reduction factor was kept fixed at 0.75 , the value determined in the Fe K-edge EXAFS fit of $\mathrm{Li}_{2} \mathrm{Fe}_{0.8} \mathrm{Mn}_{0.2} \mathrm{SiO}_{4}$ in Ref. [29]. The coordination number of neighboring atoms was kept fixed according to the crystallographic data. According to electroneutrality, substituting $\mathrm{Ti}^{4+}$ ions by $\mathrm{Fe}^{3+}$ ions leads to formation of oxygen vacancies, which are known to be situated mainly in the phase-sharing plane of the hexagonal crystal structure of Fe-doped $\mathrm{BaTiO}_{3}(\mathrm{O}(2 / 2)$ site $) .{ }^{17,32-35}$ Thus, to verify the

Table I. Parameters of the Nearest Neighbors Around Fe Atom on Ti(1) and Ti(2) Crystallographic Sites for the 10\% Fe-Doped $\mathrm{BaTiO}_{3} \mathrm{Samples}^{2}$ Treated at Different Annealing Temperatures $\left(1250^{\circ} \mathrm{C} \text { and } 1500^{\circ} \mathrm{C}\right)^{\dagger}$

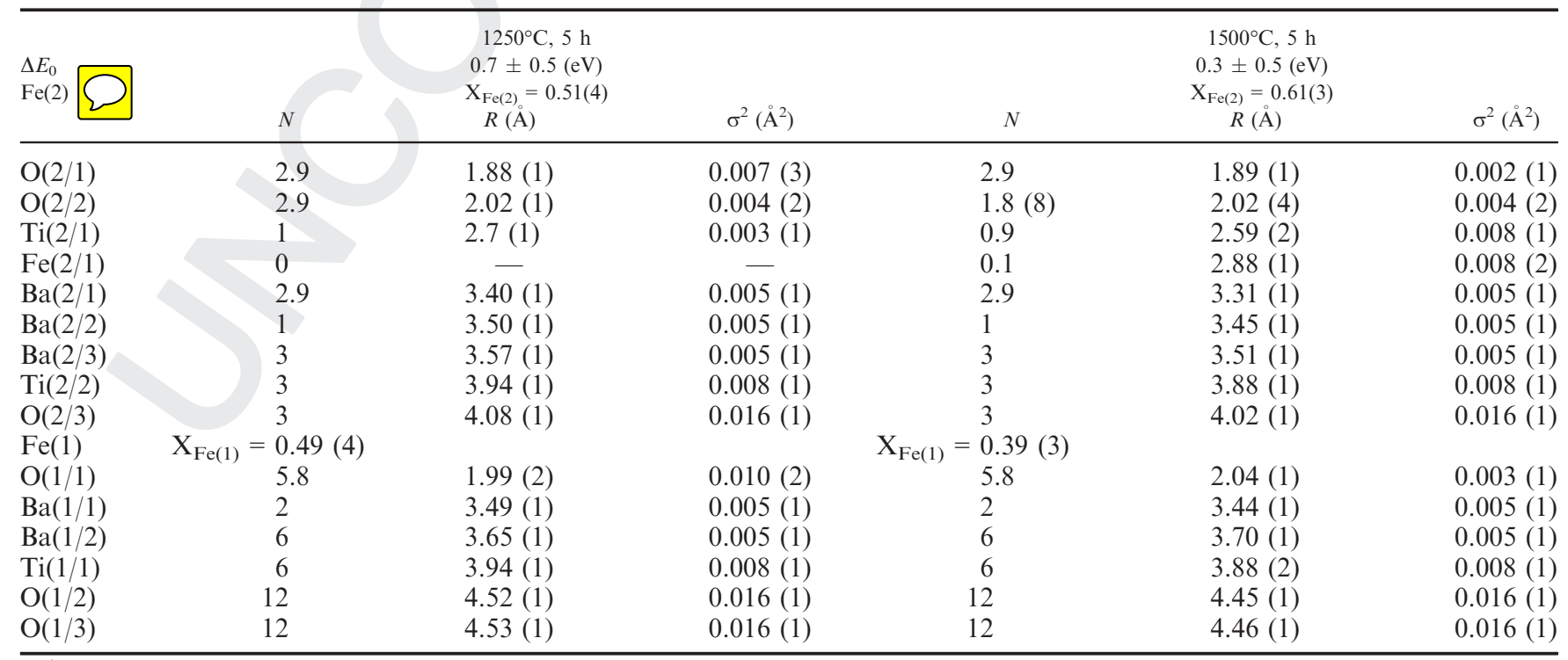

The neighbor atom annotations are based on $\mathrm{Fe}$ atoms at two crystallographic sites $[\mathrm{Ti}(1)$ and $\mathrm{Ti}(2)]$ and $\mathrm{Fe}$ neighbor atoms ordered by distance in $6 \mathrm{H}-\mathrm{BaTiO}$ crystal structure: for example, $\mathrm{O}(2 / 1)$ are oxygen neighbors of $\mathrm{Fe}(2)$ atoms located at $1.96 \AA$ $\mathrm{O}(2 / 2)$ are oxygen neighbors of Fe(2) atoms located at $1.99 \AA$.

$\mathrm{N}$, number of neighbor atoms; R, distance from the Fe atom; $\sigma^{2}$, Debye-Waller factor. 
aforementioned statement the $\mathrm{O}(2 / 2)$ coordination number was allowed to vary separately. Also, the coordination number of the $\mathrm{Fe}(2 / 1)$ atoms was varied in purpose to verify the formation of $\mathrm{Fe}$ pairs in the $\mathrm{Ti}_{2} \mathrm{O}_{9}$ polyhedra (i.e., $\mathrm{Fe}_{2} \mathrm{O}_{9}$ ). For $\mathrm{Fe}(2)-\mathrm{Fe}(2 / 1)$ and $\mathrm{Fe}(2)-\mathrm{Ti}(2 / 1)$ paths the same DebyeWaller factor was used. $\mathrm{Fe}(2)-\mathrm{Fe}(2 / 1)$ distance was allowed to very separately. Simultaneous fit of the two EXAFS spectra was carried out with intent to stabilize the fit by increasing the number of independent points and decreasing the number of variables. Thus, to minimize number of variables some of the parameters in the simultaneous relaxation were constrained to the common values for the two samples, in particular, Debye-Waller factor for $\mathrm{Fe}(2)-\mathrm{O}(2 / 2)$ path and $\mathrm{Fe}(2)-\mathrm{Ba}(2 / 1)$ distance and Debye temperature parameter.

A very good agreement between the model and the experimental spectrum of $10 \% \mathrm{Fe}$-doped $\mathrm{BaTiO}_{3}$ was found in the R-range from 1.1 to $3.9 \AA$ and in the $k$-interval $4.3-12 \AA^{-1}$ using $k^{2}$-weight for sample treated at $1250^{\circ} \mathrm{C}$ and $k^{3}$-weight for sample additionally annealed at $1500^{\circ} \mathrm{C}$.

A unit cell of $6 \mathrm{H}-\mathrm{BaTiO}_{3}$ contains six octahedrally coordinated $\mathrm{Ti}^{4+}$ ions: two at $\mathrm{Ti}(1)$ and four at $\mathrm{Ti}(2)$ sites. Therefore, in a case of random distribution $2 / 3$ of Fe ions occupy $\operatorname{Ti}(2)$ sites, whereas other $1 / 3$ occupy $\mathrm{Ti}(1)$ crystallographic sites. In our case, quantitative EXAFS analysis reveals that after heat treatment at $1250^{\circ} \mathrm{C}$ about half of all $\mathrm{Fe}$ atoms preferably occupy the $\mathrm{Ti}(1)$ crystallographic sites, whereas the other half of Fe atoms occupy $\mathrm{Ti}(2)$ site (Fig. 5). For sample fired at $1250^{\circ} \mathrm{C}$ for $5 \mathrm{~h}$ the number of oxygen vacancies in $\mathrm{O}(2 / 2)$ crystallographic site was below detection limit, so the coordination number of $\mathrm{O}(2 / 2)$ atoms was fixed to 2.94, value, which corresponds to the random distribution of oxygen vacancies around $\mathrm{Fe}(2)$ in the sample. No formation of Fe pairs has been detected (Table I). For the neighboring atoms we did not find significant distortion, except a slight relaxation of interatomic distances.

After additional annealing at $1500^{\circ} \mathrm{C}$ about $10 \%$ of iron atoms redistributed from $\mathrm{Ti}(1)\left(\mathrm{X}_{\mathrm{Fe}(1)}=40 \%\right)$ to $\mathrm{Ti}(2)\left(\mathrm{X}_{\mathrm{Fe}}\right.$ (1) $=60 \%$ ) site. The redistribution is most probably driven by the same driving force as established in Ref. [26]: reduction in electrostatic repulsion within $\mathrm{Ti}_{2} \mathrm{O}_{9}$ face-sharing octahedral. In contrast to $20 \% \mathrm{Fe}$-doped $\mathrm{BaTiO}_{3}$, during the fit procedure the number of $\mathrm{Fe}(2)-\mathrm{Fe}(2 / 1)$ pairs in $10 \% \mathrm{Fe}-$ doped $\mathrm{BaTiO}_{3}$ sample could not be reliably determined by varying the coordination number of the $\mathrm{Fe}(2 / 1)$ neighbor atoms. However, it was found that fixing the coordination number of the $\mathrm{Fe}(2 / 1)$ neighbor atoms to the 0.1 improves the fit. For this sample ordering of the oxygen vacancies by varying the coordination number of the $\mathrm{O}(2 / 2)$ atoms was detected.

Our studies show that very subtle differences exist in the cation ordering processes of different $\mathrm{Fe}$-doped $6 \mathrm{H}-\mathrm{BaTiO}_{3}$ samples. Despite these differences the ordering process is always associated with induction of the room-temperature ferromagnetism. Based on our analysis, the ferromagnetism appears independently from existence of the $\mathrm{Fe}-\mathrm{Fe}$ pairs or the oxygen vacancy segregation at $\mathrm{O}(2 / 2)$ site. These two crystallographic features are most frequently considered as an origin of the magnetic coupling in this system. Here, we showed that in the ferromagnetic $10 \%$ Fe-doped $6 \mathrm{H}-\mathrm{BaTiO}_{3}$ no significant formation of $\mathrm{Fe}-\mathrm{Fe}$ pairs exists while previously $^{26}$ has already been shown that the ferromagnetism can also exist without the segregation of oxygen vacancies in $\mathrm{O}$ $(2 / 2)$ site. However, it has been undoubtedly seen that the induction of the ferromagnetism is in some way associated with the high-temperature annealing and most probably with the observed diffusion processes but it extrinsic character still cannot be fully disregarded.

\section{Conclusions}

$2 \%$ and $10 \%$ Fe-doped $\mathrm{BaTiO}_{3}$ samples were synthesized by the solid-state reaction method at different annealing temperatures. The $2 \%$-doped $\mathrm{BaTiO}_{3}$ samples were found to be paramagnetic at RT after both annealing temperatures. The $10 \%$ Fe-doped $\mathrm{BaTiO}_{3}$ sample treated at $1250^{\circ} \mathrm{C}$ is paramagnetic, whereas $10 \%$ Fe-doped $\mathrm{BaTiO}_{3}$ sample additionally annealed at $1500^{\circ} \mathrm{C}$ exhibited ferromagnetic behavior. Fe and $\mathrm{Ti}$ K-edge XANES analysis showed no variations in the valance state of $\mathrm{Fe}^{3+}$ and $\mathrm{Ti}^{4+}$ cations in all $10 \% \mathrm{Fe}$-doped $\mathrm{BaTiO}_{3}$ samples. A Fe K-edge EXAFS analysis of the $10 \%$ Fe-doped $\mathrm{BaTiO}_{3}$ sample treated at $1250^{\circ} \mathrm{C}$ revealed that $\mathrm{Fe}^{3+}$ ions preferably occupied the $\operatorname{Ti}(1)$ sites. At this synthesis step no preferential distribution of oxygen vacancies has been detected. During the additional annealing at $1500^{\circ} \mathrm{C}$ for $10 \mathrm{~h} \mathrm{a}$ redistribution of the $\mathrm{Fe}$ cations from the $\mathrm{Ti}(1)$ sites to $\mathrm{Ti}(2)$ sites was detected, resulting in a random distribution of the $\mathrm{Fe}$ cations over these sites. Such redistribution was accompanied by segregation of oxygen vacancies on the $\mathrm{O}(2 / 2)$ site. The induction of the ferromagnetism coincides with the appearance of the observed diffusion processes. However, none of the diffusion processes can be undoubtedly identified as the one that induces the ferromagnetic spin coupling.

\section{Acknowledgments}

This work has been supported by the Slovenian Research Agency Research Programmes P1-0112, P2-0377, and PR-04988, project N2-0005, DESY and the European Community's FP7 Programme (FP7/2007-2013) under grant agreement CALIPSO n_312284 (EU Support of Access to Synchrotrons/FELs in Europe). Access to synchrotron radiation facilities of HASYLAB (project I20110082 EC) and ELETTRA (project 20110127) is acknowledged. We thank Roman Chernikov and Edmund Welter of HASYLAB and Giuliana Aquilanti of ELETTRA for expert advice on beamline operation. The CENN Nanocenter is acknowledged for the usage of the VSM.

\section{References}

${ }^{1}$ J. M. D. Coey, "Dilute Magnetic Oxides," Curr. Opin. Solid St M, 10 [2] 83-92 (2006).

${ }^{2}$ S. A. Chambers, T. C. Droubay, C. M. Wang, K. M. Rosso, S. M. Heald, D. A. SchwartZ, K. R. Kittilstved, and D. R. Gamelin, "Ferromagnetism in Oxide Semiconductors," Mater. Today, 9 [11] 28-35 (2006).

${ }^{3}$ T. Dietl, "A Ten-Year Perspective on Dilute Magnetic Semiconductors and Oxides," Nat. Mater., 9 [12] 965-74 (2010).

${ }^{4}$ P. Sharma, A. Gupta, K. V. Rao, F. J. Owens, R. Sharma, R. Ahuja, J. M. O. Guillen, B. Johansson, and G. A. Gehring, "Ferromagnetism Above Room Temperature in Bulk and Transparent Thin Films of Mn-Doped ZnO," Nat. Mater., 2 [10] 673-7 (2003).

${ }^{5}$ A. Punnoose, J. Hays, A. Thurber, M. H. Engelhard, R. K. Kukkadapu, C. Wang, V. Shutthanandan, and S. Thevuthasan, "Development of HighTemperature Ferromagnetism in $\mathrm{SnO}_{2}$ and Paramagnetism in $\mathrm{SnO}$ by Fe Doping," Phys. Rev. B, 72 [5]?????? (2005).

${ }^{6}$ D. C. Kundaliya, S. B. Ogale, S. E. Lofland, S. Dhar, C. J. Metting, S. R. Shinde, Z. Ma, B. Varughese, K. V. Ramanujachary, L. Salamanca-Riba, and T. Venkatesan, "On the Origin of High-Temperature Ferromagnetism in the Low-Temperature-Processed Mn-Zn-O System," Nat. Mater., 3 [10] 709-14 (2004)

${ }^{7}$ R. Adhikari, A. K. Das, D. Karmakar, T. V. C. Rao, and J. Ghatak, "Structure and Magnetism of Fe-Doped SnO(2) Nanoparticles," Phys. Rev. B, 78 [2] ???-??? (2008).

${ }^{8}$ X. K. Wei, T. Zou, F. Wang, Q. H. Zhang, Y. Sun, L. Gu, A. Hirata, M. W. Chen, Y. Yao, C. Q. Jin, and R. C. Yu, "Origin of Ferromagnetism and Oxygen-Vacancy Ordering Induced Cross-Controlled Magnetoelectric Effects at Room Temperature," J. Appl. Phys., 111 [7] ?????? (2012).

${ }^{9}$ J. J. Wei, N. Zhang, J. F. Fan, X. M. Yin, and H. X. Cao, "Magnetoelectric Effect in Bilayer Composites of Fe-Doped BaTiO(3) and Terfenol-D," $J$. Phys.-Condensed Matter, 20 [8]??????? (2008).

${ }^{10}$ X. K. Wei, Y. T. Su, Y. Sui, Q. H. Zhang, Y. Yao, C. Q. Jin, and R. C. $\mathrm{Yu}$, "Structure, Electrical and Magnetic Property Investigations on Dense Fe-Doped Hexagonal $\mathrm{BaTiO}_{3}, "$ J. Appl. Phys., 110 [11] ??????? (2011)

${ }^{11}$ X. K. Wei, L. D. Yao, X. Shen, Y. Yang, S. J. You, F. Y. Li, C. Q. Jin, and R. C. Yu, "Structural Modulation and Magnetic Properties of Hexagonal $\mathrm{Ba}\left(\mathrm{Ti}_{1-\mathrm{X}} \mathrm{Fe}_{\mathrm{x}}\right) \mathrm{O}_{3}$-Delta Ceramics," Phys. B, 405 [23] 4851-4 (2010).

${ }^{12}$ S. Ray, P. Mahadevan, S. Mandal, S. R. Krishnakumar, C. S. Kuroda, T. Sasaki, T. Taniyama, and M. Itoh, "High Temperature Ferromagnetism in Single Crystalline Dilute Fe-Doped BaTiO(3)," Phys. Rev. B, 77 [10] ???-??? (2008).

${ }^{13}$ N. V. Dang, T. D. Thanh, L. V. Hong, V. D. Lam, and T. L. Phan, "Structural, Optical and Magnetic Properties of Polycrystalline BaTi $i_{1-} \mathrm{Fe}_{\mathrm{x}} \mathrm{O}_{3}$ Ceramics," J. Appl. Phys., 110 [4] ???-??? (2011).

${ }^{14}$ G. Radaelli, D. Petti, E. Plekhanov, I. Fina, P. Torelli, B. R. Salles, M. Cantoni, C. Rinaldi, D. Gutiérrez, G. Panaccione, M. Varela, S. Picozzi, J. Fontcuberta, and R. Bertacco, "Electric Control of Magnetism at the Fe/Ba$\mathrm{TiO}_{3}$ Interface," Nat. Commun., 5, ??????? (2014). 
${ }^{15}$ Z. G. Guo, L. H. Yang, H. M. Qiu, X. D. Zhan, J. H. Yin, and L. P. Cao, "Structural, Magnetic and Dielectric Properties of Fe-Doped $\mathrm{BaTiO}_{3}$ Sol12 ids," Mod. Phys. Lett. B, 26 [9]???-??? (2012).

${ }^{16}$ F. T. Lin, D. M. Jiang, X. M. Ma, and W. Z. Shi, "Effect of Annealing Atmosphere on Magnetism for Fe-Doped $\mathrm{BaTiO}_{3}$ Ceramic," Phys. B, 403 [17] 2525-9 (2008)

${ }^{17}$ F. T. Lin, D. M. Jiang, X. M. Ma, and W. Z. Shi, "Influence of Doping Concentration on Room-Temperature Ferromagnetism for Fe-Doped $\mathrm{BaTiO}_{3}$ Ceramics," J. Magn. Magn. Mater., 320 [5] 691-4 (2008).

${ }^{18}$ F. T. Lin and W. Z. Shi, "Effects of Doping Site and Pre-Sintering Time on Microstructure and Magnetic Properties of Fe-Doped $\mathrm{BaTiO}_{3}$ Ceramics," Phys. B, 407 [3] 451-6 (2012).

${ }^{19}$ F. T. Lin and W. Z. Shi, "Influence of Non-Isovalent Ion Substitution at A Site on Microstructure and Magnetic Properties of $\mathrm{Ba}\left(\mathrm{Ti}_{0.3} \mathrm{Fe}_{0.7}\right) \mathrm{O}-3$ Ceramic," J. Alloy. Compd., 495 [1] 167-72 (2010).

${ }^{20}$ A. Rajamani, G. F. Dionne, D. Bono, and C. A. Ross, "Faraday Rotation, Ferromagnetism, and Optical Properties in Fe-Doped $\mathrm{BaTiO}_{3}$," J. Appl.

13 Phys., 98 [6] ???-??? (2005).

${ }^{21}$ S. Y. Qiu, W. Li, Y. Liu, G. H. Liu, Y. Q. Wu, and N. Chen, "Phase Evolution and Room Temperature Ferroelectric and Magnetic Properties of Fe-Doped $\mathrm{BaTiO}_{3}$ Ceramics," Trans. Nonferrous Metals Soc. China, 20 [10] 1911-5 (2010)

${ }^{22}$ T. A. Vanderah, J. M. Loezos, and R. S. Roth, "Magnetic Dielectric Oxides: Subsolidus Phase Relations in the $\mathrm{BaO}: \mathrm{Fe}_{2} \mathrm{O}_{3}: \mathrm{TiO}_{2}$ System," J. Solid State Chem., 121 [1] 38-50 (1996).

${ }^{23}$ H. M. Nguyen, N. V. Dang, P. Y. Chuang, T. D. Thanh, C. W. Hu, T. Y. Chen, V. D. Lam, C. H. Lee, and L. V. Hong, "Tetragonal and Hexagonal Polymorphs of $\mathrm{BaTi}_{1-\mathrm{X}} \mathrm{Fe}_{\mathrm{x}} \mathrm{O}_{3}$-Delta Multiferroics Using X-ray and Raman

14 Analyses," Appl. Phys. Lett., 99 [20] ??????? (2011).

${ }^{24}$ T. Chakraborty, S. Ray, and M. Itoh, "Defect-Induced Magnetism: Test of Dilute Magnetism in Fe-Doped Hexagonal $\mathrm{BaTiO}_{3}$ Single Crystals," Phys.

15 Rev. B, 83 [14] ?????? (2011).
${ }^{25}$ T. Chakraborty, C. Meneghini, G. Aquilanti, and S. Ray, "Microscopic Distribution of Metal Dopants and Anion Vacancies in Fe-Doped $\mathrm{BaTiO}_{3}$ Delta Single Crystals," J. Phys.-Condensed Matter, 25 [23] ???-??? (2013).

${ }^{26}$ M. Valant, I. Arčon, I. Mikulska, and D. Lisjak, "Cation Order-Disorder Transition in Fe-Doped $6 \mathrm{H}-\mathrm{BaTiO}_{3}$ for Dilute Room-Temperature Ferromagnetism," Chem. Mater., 25 [17] 3544-50 (2013).

${ }^{27}$ B. Ravel and M. Newville, "Athena, Artemis, Hephaestus: Data Analysis for X-ray Absorption Spectroscopy Using IFEFFIT," J. Synchrotron Radiat., 12, 537-41 (2005).

${ }^{28}$ I. Arcon, J. Kolar, A. Kodre, D. Hanzel, and M. Strlic, "XANES Analysis of Fe Valence in Iron Gall Inks," X-Ray Spectrom., 36 [3] 199-205 (2007).

${ }^{29}$ R. Dominko, C. Sirisopanaporn, C. Masquelier, D. Hanzel, I. Arcon, and M. Gaberscek, "On the Origin of the Electrochemical Capacity of $\mathrm{Li}_{2} \mathrm{Fe}_{0.8}$ $\mathrm{Mn}_{02} \mathrm{SiO}_{4}, " J$. Electrochem. Soc., 157 [12] A1309-16 (2010).

${ }^{30}$ J. J. Rehr, R. C. Albers, and S. I. Zabinsky, "High-Order Multiple-Scattering Calculations of X-Ray-Absorption Fine-Structure," Phys. Rev. Lett., 69 [23] 3397-400 (1992).

${ }^{31}$ J. Akimoto, Y. Gotoh, and Y. Oosawa, "Refinement of Hexagonal Ba$\mathrm{TiO}_{3}$," Acta Crystallogr. Sec. C, 50 [2] 160-1 (1994).

${ }^{32}$ I. E. Grey, C. Li, L. M. D. Cranswick, R. S. Roth, and T. A. Vanderah, "Structure Analysis of the $6 \mathrm{H}-\mathrm{Ba}\left(\mathrm{Ti}, \mathrm{Fe}^{3+}, \mathrm{Fe}^{4+}\right) \mathrm{O}^{3-} \Delta$ Solid Solution," $J$. Solid State Chem., 135 [2] 312-21 (1998).

${ }^{33}$ E. Mashkina, C. McCammon, and F. Seifert, "A Mossbauer Study of Oxygen Vacancy and Cation Distribution in $6 \mathrm{H}-\mathrm{BaTi}_{1-\mathrm{x}} \mathrm{Fe}_{\mathrm{x}} \mathrm{O}_{3-\mathrm{x} / 2}$," J. Solid State Chem., 177 [1] 262-7 (2004).

${ }^{34}$ I. E. Grey, L. M. D. Cranswick, and C. Li, "Accurate Site Occupancies for Light Atoms From Powder X-ray Data? Oxygen Vacancy Ordering in 6H$\mathrm{BaFe}_{0.67} \mathrm{Ti}_{0.33} \mathrm{O}_{3}$-Delta (Delta $=0.08$ and 0.32)," J. Appl. Crystallogr., 31, 6929 (1998).

${ }^{35}$ T. A. Colson, M. J. S. Spencer, and I. Yarovsky, "A DFT Study of the Perovskite and Hexagonal Phases of $\mathrm{BaTiO}_{3}$," Comp. Mater. Sci., 34 [2] 15765 (2005). 


\section{Author Query Form}

\section{Journal: $\quad$ JACE}

Article: $\quad 13408$

Dear Author,

During the copy-editing of your paper, the following queries arose. Please respond to these by marking up your proofs with the necessary changes/additions. Please write your answers on the query sheet if there is insufficient space on the page proofs. Please write clearly and follow the conventions shown on the attached corrections sheet. If returning the proof by fax do not write too close to the paper's edge. Please remember that illegible mark-ups may delay publication.

Many thanks for your assistance.

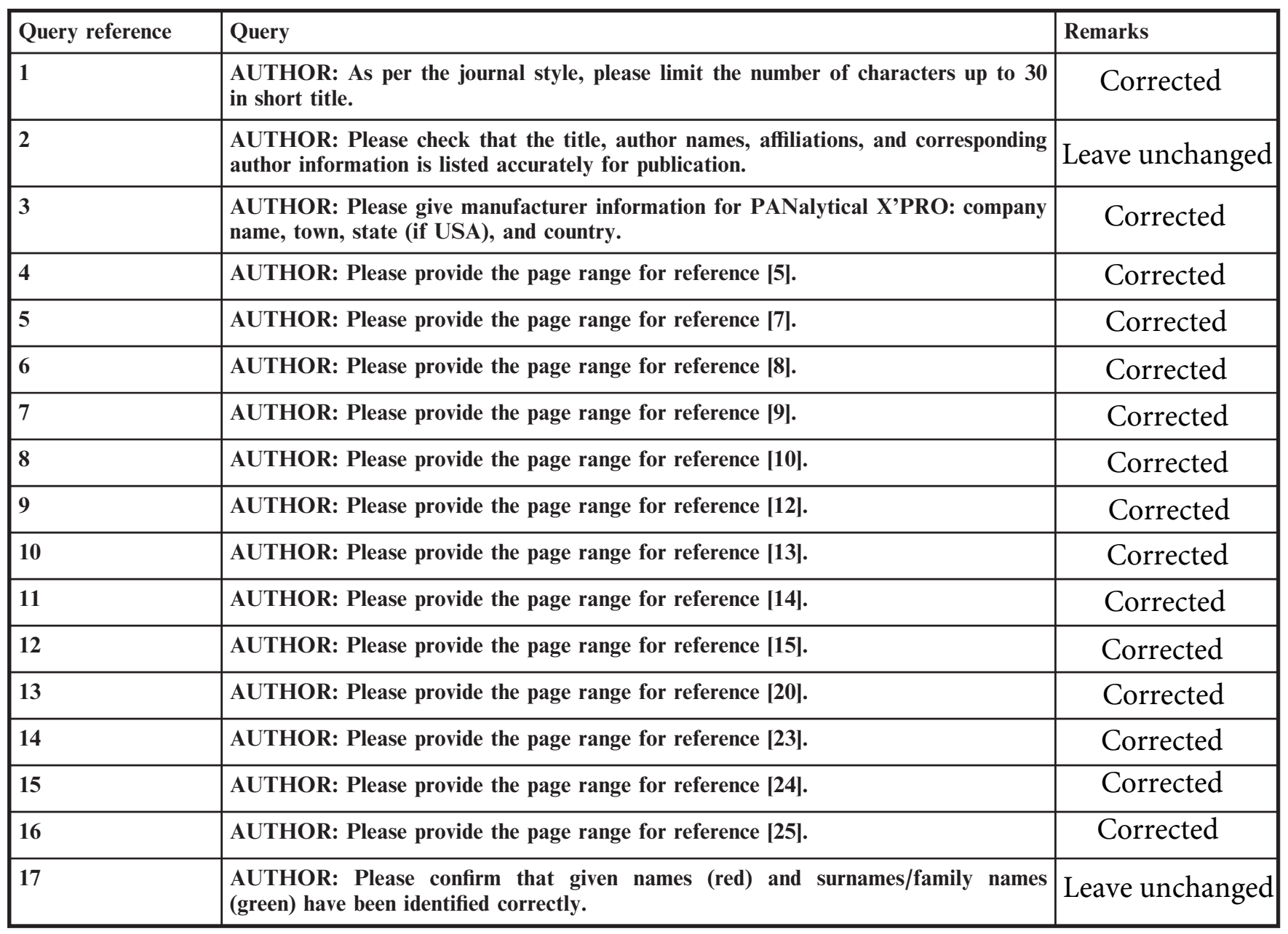




\section{Proof Correction Marks}

Please correct and return your proofs using the proof correction marks below. For a more detailed look at using these marks please reference the most recent edition of The Chicago Manual of Style and visit them on the Web at: http://www.chicagomanualofstyle.org/home. html

\begin{tabular}{|c|c|c|}
\hline Instruction to typesetter & Textual mark & Marginal mark \\
\hline Leave unchanged & ... under matter to remain & (stet) \\
\hline $\begin{array}{l}\text { Insert in text the matter } \\
\text { indicated in the margin }\end{array}$ & $\wedge$ & $\begin{array}{l}\wedge \text { followed by new } \\
\text { matter }\end{array}$ \\
\hline Delete & $\begin{array}{l}\sigma_{\text {through single character, rule or underline }} \\
\text { or }\end{array}$ & matter \\
\hline $\begin{array}{l}\text { Substitute character or } \\
\text { substitute part of one or } \\
\text { more word(s) }\end{array}$ & $\begin{array}{l}\sigma \text { through all characters to be deleted } \\
K \text { through letter or } \\
\longrightarrow \text { through characters }\end{array}$ & $\begin{array}{l}\text { new character } \lambda \text { or } \\
\text { new characters } \lambda\end{array}$ \\
\hline Change to italics & — under matter to be changed & ital \\
\hline Change to capitals & $\equiv$ under matter to be changed & (caps \\
\hline Change to small capitals & $=$ under matter to be changed & (sc) \\
\hline Change to bold type & $\sim$ under matter to be changed & (bf) \\
\hline Change to bold italic & $\bar{\sim}$ under matter to be changed & bf+ital \\
\hline Change to lower case & B & (2) \\
\hline Insert superscript & $\checkmark$ & $\begin{array}{l}\checkmark \text { under character } \\
\text { e.g. } v\end{array}$ \\
\hline Insert subscript & $\wedge$ & $\begin{array}{l}\wedge \text { over character } \\
\text { e.g. } \hat{\Sigma}\end{array}$ \\
\hline Insert full stop & $\odot$ & $\odot$ \\
\hline Insert comma & $\hat{\jmath}$ & $\hat{\jmath}$ \\
\hline Insert single quotation marks & $\sqrt{2}$ & $\sqrt{2}$ \\
\hline Insert double quotation marks & $\ddot{*}$ & $\ddot{w}$ \\
\hline Insert hyphen & $=$ & $=$ \\
\hline Start new paragraph & 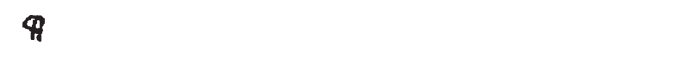 & $\Phi$ \\
\hline Transpose & $\sqcup$ & $\sqcup$ \\
\hline Close up & linking $\bigcirc$ characters & 2 \\
\hline $\begin{array}{l}\text { Insert or substitute space } \\
\text { between characters or words }\end{array}$ & $\#$ & \# \\
\hline $\begin{array}{l}\text { Reduce space between } \\
\text { characters or words }\end{array}$ & J & こ \\
\hline
\end{tabular}

